\title{
A typical patient with depression?
}

\section{A comparative linguistic analysis of accounts by general practitioners and psychiatrists}

\section{Hanne Sæderup Pedersen ${ }^{1}$}

Annette Sofie Davidsen ${ }^{2}$
${ }^{1}$ Department of Nordic Studies and Linguistics, University of Copenhagen sbc846@hum.ku.dk
${ }^{2}$ Research Unit for General Practice and Section of General Practice, University of Copenhagen
sbc846@hum.ku.dk

Pedersen, Hanne Sæderup \& Davidsen, Annette Sofie (2019) A typical patient with depression: A comparative linguistic analysis of accounts by general practitioners and psychiatrists Tidsskrift for Forskning i Sygdom og Samfund nr 31, 107-126

In Denmark and internationally there is a push for enhanced collaboration between general practice and the psychiatric sector in the treatment of patients with depression. Linguistic and other qualitative studies into doctor-patient interaction have shown that general practitioners (GPS) and psychiatrists have different understandings of depression, which could hamper collaboration. The present study adds to linguistic research of the understanding of depression in the two sectors by examining healthcare communication in a context of representation: how doctors talk about their patients in interviews, rather than how they communicate with their patients in consultations. We demonstrate that the two groups of doctors have diverging representations of patients with depression. Most GPs present patients as individuals whose condition is explained by psychosocial circumstances; whereas psychiatrists predominantly present patients as categories. This difference is evidenced by 
how the two groups respond to the interviewer's elicitation of patient stories. The GPS employ personal or specific narrative genres, whereas the psychiatrists use general narrative genres, indicating that the two groups occupy their own separate spaces within what is termed the narrative field. We also demonstrate that these different representations concur with variations in interactional patterns in the interview context, enhancing the gap between the professional identities of the two groups of doctors and, consequently, their conceptualizations of depression. The difference between the groups could be suggestive of cultural differences between the two sectors, caused by their different roles and working conditions in the health care system, which could pose a challenge to future cooperation.

\section{Introduction}

In Denmark, as in other countries, there has been an expressed wish to establish shared care between general practice and psychiatry for the increasing number of patients with depression (Gask 2005, Eplov, Lundsteen \& Birket-Smith 2009, Eplov et al. 2014). In the US and the UK in particular, different collaborative care models have been introduced and tested with moderate results and with outcomes dependent on the health care system in each country (Archer et al. 2012, Richards et al. 2016, Coventry et al. 2012). In Denmark, a collaborative care model is currently being tested (Brinck-Claussen et. al 2017). There is a growing awareness, however, that effective collaboration is dependent upon shared understanding among professionals (May 2013).

Studies using interactional linguistic or other qualitative methods have shown different understandings of depression in general practice and in psychiatry (e.g. Davidsen \& Fosgerau 2014a, Davidsen \& Fosgerau 2014b, Fosgerau \& Davidsen 2014). To further explore the understandings of depression among general practitioners (GPs) and psychiatrists (PSs) in Denmark, this article will apply a representational linguistic method by looking at how the doctors construct patient identities in an interview setting. More specifically, our aim is to examine how GPS and PSs conceptualize a typical patient with depression. In addition, interactional phenomena between interviewer and interviewees are taken into consideration to provide a full picture of the two groups' views of their patients.

Linguistic investigations of medical discourse have dealt with doctor-patient interaction (for a review see Nielsen 2010). They are typically within the framework of Conversation Analysis, focusing on interactional settings (e.g. Sacks et al. 1974, Heritage \& Maynard 2006, Davidsen \& Fosgerau 2014a, Fosgerau \& Davidsen 2014); 
or they have used Critical Discourse Analysis, focusing on how e.g. pre-defined power structures are expressed in the interaction (Fairclough 1989, Wodak 1997). In contrast, how doctors talk about patients is treated by other sciences (e.g. ChewGraham, Davidsen 2008, Davidsen \& Fosgerau 2014b) that have also included the narrative perspective (Davidsen \& Reventlow 2011).

The narrative perspective has gained increasing influence within different forms of science since about 1980, e.g. philosophy, psychology and law (Ricoeur 1980, Schafer 1980), leading to what is called the narrative turn (Sarbin 1986, Jensen \& Mattingly 2009) with incorporation of narrative conceptualizations into a broad variety of fields (e.g. Bamberg 2010, Bruner 1986, 2002 and White 2007). Additionally, there is an increased emphasis in the medical literature on the value and importance of language in working with depressed patients (Dowrick 2009). Dowrick represents a constructionist view of language and sees narrative as a tool, which has the capacity to shape our own and others' selves (Dowrick 2009, p. 219). Building on this widely accepted concept, we argue that language and narrative are not only central to the interaction with patients as tools to encourage them to tell their stories, but language also plays a central role in reflecting and shaping the reality of the professionals treating the patients.

Choosing the interview as the object of investigation provides an opportunity for supplementary representational perspectives to the studies of doctor-patient interactions. We apply this perspective to the medical professionals in interviews talking about their patients.

\section{Method}

\section{Data collection}

The informants were 12 GPs and 11 PSs, selected purposively from two regions in Denmark to control for the range of demographic differences among the doctors, all of whom were covered by a collective agreement with the health authorities or employed at a public hospital. The gender distribution was equal in the two groups; the age range was comparable, for the PSs 45-62 years and for the GPs 4366 years. The data consisted of semi-structured interviews (Kvale 1997) conducted by the second author who is a GP and who has also worked in psychiatry. Before conducting the actual interview, the interviewer informed the participants of this 
professional background. Thus, the interviewer's experience from both fields provided an opening for possible alignment with both groups of professionals. An interview guide was designed to ensure that all desired domains were covered and to consider foreseen difficulties. The guide was suggestive, not prescriptive. The questions were neutral, open and addressed the participants' understandings and conceptualizations of depression (Smith \& Osborn 2003). The interviews were not conducted with the present study in mind. Rather, the present study was motivated by an observation that the interviews were generally non-narrative. We wished, therefore, to identify passages in the interviews that specifically encouraged narrative accounts. We elaborate on this approach below. The interviews were audio-recorded and transcribed according to the Clan conventions (Clan transcription conventions 2018).

\section{Demarcation of the genres}

Our object of interest was an elicitation question worded along the lines of 'Do you remember a typical patient with depression?' or 'Do you remember a patient story?' Although, this question was not included in the interview guide (see above), it occurred in most interviews ${ }^{1}$. The recurrence of this question makes the speech situation across the interviews comparable (cf. also Gregersen \& BarnerRasmussen 2011). The research interview is a genre in which the interviewer is trying to obtain information, and the interviewee is the provider of this information (Kvale 1997: 19). The current interviews were one-to-one interviews, meaning that there was no competition for the right to the floor and the interviewees were therefore relatively free to elaborate the answers as they wished (e.g. Møller 1993: 294-5). This uncompetitive setting often resulted in rather long, monologic stretches of speech, some of which were narrative in that they presented chronologically ordered past events (Eggins \& Slade 1997, Gregersen \& Barner-Rasmussen 2011). It is such narrative stretches prompted by the elicitation question that this study is concerned with: what did the two groups of doctors do when presented with an elicitation question within an uncompetitive frame?

\section{Additional analyses}

In addition to narrative genres, we examined interactional phenomena associated with the production of the doctors' narrative genres. These phenomena include the grammatical number in question-answer sequencings, as well as negotiations 
of the interviewer's elicitation question. To substantiate our argumentation, we also look at the thematic content of the narrative genres.

\section{Theoretical framwork: The narrative genres}

Departing from classic sociolinguistic narrative theory (Labov \& Waletzsky 1967), which views narratives as projecting social and cultural identities, we argue that speakers' linguistic choices play a determining role in their conceptualizations of patients with depression. Therefore, a linguistically founded narrative framework can provide a fine-grained approach to narrative investigations of understandings of patients with depression. The study is based on an analysis of three different speech genres: the personal narrative, the specific account and the general account. These three types of narrative genre are based on findings from studies of language change at the LANCHART Centre at the University of Copenhagen, where a large corpus study of so-called sociolinguistic interviews has suggested that the narrative field is covered by these three genres (Gregersen \& Barner-Rasmussen 2011:15). The three genres are replicated below.

\section{The personal narrative and the specific account}

The most well-established of the three genres is the personal narrative as defined by the sociolinguist William Labov (e.g. Labov \& Waltezky 1967, Labov 1972). Through a study of New Yorkers' narratives about their experiences of life-threatening situations, Labov discovered a recurrent structure in the way the informants told stories (Labov \&Waletzky 1967: 26). Labov views the overall narrative structure "[...] as a series of answers to underlying questions [...]" (Labov 1972: 370) followed by a coda:
A. Abstract: what was this about?
B. Orientation: who, when, what, where?
C. Complicating Action: then what happened?
D. Evaluation: so what?
E. Result: what finally happened?
F. Coda 
The last element, coda, closes the narrative by bridging the narrative world and the current speech situation (Labov 1972: 370). Of the six elements, Complicating Action and Evaluation are obligatory (Eggins \& Slade 1997: 237). Further, for the story to qualify as a personal narrative it must be rendered as reportable and be centred on one unique event, implying a climax and a subsequent resolution, and the narrator must have been a participant in the narrated events (Labov 1972: 355, Labov 1997: 7-8).

The specific account is similar to the personal narrative in focusing on a specific event in the past. Regarding participation, the narrator must have been a participant in, or at least a witness to, the event. The mode differs from that of the personal narrative in treating the event in a descriptive rather than in a performed mode, just as the focus is on the process rather than on a central event. This mode is typically realized as listing events, using 'and then... and then... and then...', and the amount of detail is less than in a personal narrative (Eggins \& Slade 1997: 259). The specific account may contain some of the same elements as those described in the personal narrative, but the only obligatory element is the chronological rendering of a sequence of events (Eggins \& Slade 1997).

\section{The general account}

The general account is a rendering of recurrent past events, routines or habits, or general processes and sequences, and thus differs from the other two narrative genres in terms of specificity (Gregersen \& Barner-Rasmussen 2011: 15-16). As in the specific account, this narrative mode is descriptive rather than performed. In contrast to the two other narrative genres, the general account need not be selfexperienced (LANCHART, 2011: 44).

All three genres are narrative in structure and serve to present a progression. They do, however, differ in degrees of specificity and detail, reportability and evaluation (see also Table 1 below). In relation to these parameters, the personal narrative represents one end of the narrative field or spectrum, and the general account the other. Central to the present study is, however, that both the personal narrative and the specific account deal with the particular and, therefore, serve to project a specific patient. This specificity makes these two genres fundamentally different from the general account, which, as we will show, the doctors employ to talk about patients as a generic group. The assumption for the present study is that the doctors' selections from the narrative field indicate how they conceptualize patients with depression, and how they construct patient identities. 


\section{Summary of narrative speech genres}

The characteristics of the three narrative genres are summarized in the table below:

\begin{tabular}{|l|l|l|l|}
\hline Narrative genres & Personal narrative & Specific account & General account \\
\hline Participation & Central role & Central role & No requirement \\
\hline Narrative mode & $\begin{array}{l}\text { Specific, } \\
\text { performed }\end{array}$ & $\begin{array}{l}\text { Specific, } \\
\text { descriptive }\end{array}$ & $\begin{array}{l}\text { General, } \\
\text { descriptive }\end{array}$ \\
\hline Reportability & Reportable & Non-reportable & $\begin{array}{l}\text { Reportable or } \\
\text { non-reportable }\end{array}$ \\
\hline Obligatory elements & $\begin{array}{l}\text { Complicating acti- } \\
\text { on and evaluation }\end{array}$ & $\begin{array}{l}\text { Chronological } \\
\text { rendering of } \\
\text { events }\end{array}$ & None \\
\hline
\end{tabular}

Table 1: Characteristics of the three narrative genres

\section{Results}

\section{Narrative Genres}

A count of the different speech genres produced by the GPs and PSs showed the following results:

\begin{tabular}{|l|l|l|l|}
\hline GENRE & Personal narrative & Specific account & General account \\
\hline $11 \mathrm{GPs}^{2}$ & 4 & 4 & 3 \\
\hline $9 \mathrm{PSs}^{3}$ & 2 & 3 & 4 \\
\hline
\end{tabular}

Table 2: Distribution of narrative genres in the GP and PS groups

The most notable difference between the two groups is the production of personal narratives (4 vs. 2). Even though the doctors were encouraged to tell a story about a typical patient, relatively few doctors produced a fully-fledged story. Regarding the number of accounts, the two groups showed similar tendencies: the GPs producing slightly more specific accounts (4 versus 3 ) and the PSs slightly more general accounts (4 versus 3 ). If we combine the genres that per se are specific, i.e. the personal narrative and the specific account, and compare these with the general genre, the general account, the tendency toward different preferences within the 
two groups is strengthened. In the GP group, 8 of 11 genres are specific, whereas this is only the case in 5 of 9 instances in the PS group. To illustrate, (1) is a personal narrative produced by a GP (GP6), where INT represents the interviewer and INF represents the interviewee or informant:

(1)

\begin{tabular}{|c|c|}
\hline Element & Personal narrative \\
\hline Elicitation & $\begin{array}{l}\text { INT: do you remember any patients? } \\
\text { INF: well I think \# I have already \# we } \\
\text { have already \# } \\
\text { INT: you just said burning <INF: \# yes } \\
\text { \#> on the tongue \{is\} it was \{n-\} is it a } \\
\text { patient who \# } \\
\text { INF: yes! it is a it \# <INT: \# has had } \\
\text { \{these symptoms\}> } \\
\text { INT: \{or\} \# yes <INF: \# yes: it ehm> \# } \\
\text { INF: well she! is not that good an } \\
\text { example it \{it\} is just because ehm \# } \\
\text { it was more because \#\{yes she\} I just } \\
\text { mentioned Lyr- \# la- la- Lyrica and } \\
\text { ehm \#<INT: \# mm> \# there were some } \\
\text { who had suggested } \\
\text { INT: yes \# } \\
\text { INF: suggested it \# } \\
\text { INT: yes \# }\end{array}$ \\
\hline Abstract & $\begin{array}{l}\text { INF: but but I think \# no what can } \\
\text { we I don't know if I can think of any } \\
\text { examples but sometimes there are } \\
\text { <INT: \# no \#> some patients where I } \\
\text { think \# yes it may well! be that it is } \\
\text { what is called somatisation but I think } \\
\text { that is also very much down the \# } \\
<\text { XAD: \# yes> \# depressive anxie- \# } \\
<\text { XAD: \# yes> alley right \# } \\
\text { INT: yes }\end{array}$ \\
\hline
\end{tabular}




\begin{tabular}{|c|c|}
\hline Orientation & $\begin{array}{l}\text { INF: ehm that ehm \# oh I have I have a } \\
\text { young Tunisian: ehm man ma- a man } \\
\text { of Tun: ehm Tunisian origin }\end{array}$ \\
\hline Complicating Action & $\begin{array}{l}\text { who \# first said that he had a \# fever } \\
\text { \# fever he said and then he did like } \\
\text { that and then <INT: \# yes \# yes> \# I } \\
\text { completely misunderstood and then I } \\
\text { showed him a thermometer and then } \\
\text { he was completely terrified \# about it } \\
\text { \# about about <INT: \# yes \# yes \#> the } \\
\text { way we measure! ha <INT: \# mm> the } \\
\text { temperature <INT: yes ha> \# }\end{array}$ \\
\hline Result & $\begin{array}{l}\text { but it turned }\{\text { out }\} \text { that he had a prick- } \\
\text { ing sensation \# } \\
\text { INT: yes \# }\end{array}$ \\
\hline Evaluation & $\begin{array}{l}\text { INF: and \# of course there is so- } \\
\text { mething: \# ethnical and cultural to } \\
\text { that! \# but \# he is co:mpletely \# out of } \\
\text { his wits because of th- <INT: \# mm> } \\
\text { because of- of- of- this thing \# } \\
\text { INT: yes \# } \\
\text { INF: a- a- and th- \# I am thinking it } \\
\text { i:t \# these are symptoms where you: \# } \\
\text { must be aware if \# if there are men- \# } \\
\text { me:ntal conditions and if it could be } \\
<\text { INT: \# yes \#> anxiety <INT: \# yes \#> \# } \\
\text { INT: yes }\end{array}$ \\
\hline Coda & $\begin{array}{l}\text { INF: anxiety depression are ehm as } \\
\text { such <INT: \# yes yes \#> \# in the medi- } \\
\text { cal field I think they have been mixed } \\
\text { \#<INT: \# yes> \# maybe a bit too much } \\
\text { together }\end{array}$ \\
\hline
\end{tabular}


In this personal narrative, the GP talks about a patient whose cultural background led to a misunderstanding in the consultation. The GP suspected that the patient's somatic symptoms could be related to a mental condition. By means of this personal narrative, the GP tries to show how somatic symptoms, in this case, combined with a different cultural and ethnical schism, may be rooted in an underlying mental condition and touches upon the importance of differentiating between various mental conditions, such as anxiety and depression.

The second excerpt (2) is a general account produced by a PS (PS6):

(2)

\section{General account}

INT: so \# how \# if you are to paint! a \# typical depression- \# \{-picture-\} or perhaps you can remember a \# certain patient! you perhaps can \#

INF: well we have a completely <INT: \# mention \#> fixed proce:- so to speak they are called into a pre-interview \# $<$ XAD: \# $\mathrm{mm}>$ now we have just changed it so that they actually must come to two! pre-interviews \#

INT: right \#

INF: but often most of it we are able \# to clarify in the first pre-interview <INT: \# yes \#> where I <INT: \# yes \#> participate and then there's also a district nurse \# <INT: \# yes $>$ \# and then we make a completely! standard anamnesis recording it takes \# just under an hour \#

INT: $\mathrm{mm}$

INF: \# mm mostly \# and go through just like when you make any \# other medical record \# \{with dispositions and allergies and <INT: \# yes> previous: \# go through all these other organ systems systematically how do you say it to: $\mathrm{mm}$ \# partly to find out if: \# they have! some kind of illness they have forgotten to tell about: \# there can be side effects \# or to \# also typically to be able to describe! if there is \# for example if they mention that they have a headache regularly so if they come back a:nd \# complain about headache in connection with start-up of medication! then we can kind of look back and say well they \# actually also had this before is it <INT: \# $\mathrm{mm} \#>$ congestion! or $<\mathrm{INT}$ : \# $\mathrm{mm} \#>$ INT: \# yes \#

INF: whatever it may be \# (PS6)

In (2) the PS describes the diagnostic process related to depression. The focus is on bodily/somatic symptoms and medical treatment rather than on a certain patient's 
life story, which could provide an explanation for the patient's depression, as was the case in the GP narrative in (1).

The thematic focus along with the general mode provides interesting information about the PS's focus and, accordingly, the PS's mindset in relation to depression. It conveys a much stronger medical and diagnostic focus than the GP's narrative in (1). We will return to differences in thematic foci later. Further, the PS's choice of genre is interesting in relation to the interviewer's question, which ends with an encouragement to highlight a specific patient: "perhaps you remember a certain patient you can tell about". However, the psychiatrist seems to overrule this encouragement by maintaining a general focus. This phenomenon will be treated in detail later. These results suggest that the GPs choose to highlight individual patients whereas the PSs conceptualize patients in more general terms, leaving out references to individual patients' stories.

\section{Thematic focus in the speech genres}

The thematic focus in the speech genres also reveals a difference between the two groups. In all of the GP elicitations, the patient's psychosocial background forms part of the storyline. The GPs tend to highlight the explanations for depression by referring to family relations, life-changing events or - as is the case in (1) - cultural and ethnic aspects. This focus is only found in 5 of 9 PS elicitations. In 3 of these 5 instances, a general account is chosen as the narrative mode, indicating that when the PSs choose to thematize patient backgrounds, the tendency is to paint a general picture of circumstances, instead of highlighting specific patients. In this way, the predominant picture established by the PS group is one of generality, which again supports the argument that this group of doctors conceptualize the psychosocial aspect of depression as a dimension that can be categorized, which is less the case with the GPs.

\section{Singular/plural phrasing of elicitation questions in relation to narrative genres}

The doctors' genres as a response to the elicitation question support their different takes on constructing depression as illustrated by the following:

(3); if you were to mention a typical patient with depression who do you think of? (question to PS1) 
(4); do you remember any stories as examples of some of those different types? (question to GP9)

In (3), the interviewer's question is posed using the singular, whereas in (4) the interviewer employs the plural form. The hypothesis behind the singular-plural distinction is that a question posed in the singular would evoke a story about a single patient realized as a specific genre, either a personal narrative or a specific account; and conversely, a question in the plural would result in a general account. ${ }^{4}$ The table below displays the correlations between the phrasing of the elicitation question and the production of genres in the two groups:

\begin{tabular}{|l|l|l|}
\hline & GP group & PS group \\
\hline $\begin{array}{l}\text { Total production of } \\
\text { genres }\end{array}$ & 11 & 9 \\
\hline $\begin{array}{l}\text { Singular } \\
\text { elicitation>specific genre }\end{array}$ & 6 & 4 \\
\hline $\begin{array}{l}\text { Singular } \\
\text { elicitation>general genre }\end{array}$ & 3 & 3 \\
\hline $\begin{array}{l}\text { Plural elicitation>specific } \\
\text { genre }\end{array}$ & 2 & 1 \\
\hline $\begin{array}{l}\text { Plural elicitation>general } \\
\text { genre }\end{array}$ & 0 & 1 \\
\hline
\end{tabular}

Table 3: Singular/plural distinction in questions and answers in the GP and PS groups

A comparison of the production of genres between the two groups in relation to the singular/plural distinction points to two conclusions. First, in the GP speaker group, both questions phrased in the plural prompt a specific genre (i.e. personal narrative or specific account). Even though a question in the plural would be expected to elicit a general genre, the GPs choose to go beyond this match and adapt the question to their own use, narrating a story about a single patient through a specific genre. This count supports the tendency that the GPs view their patients as individuals, and that the emphasis on single fates takes precedence over diagnostic processes and placing the patient in a certain category of illness. Second, in 3 of 9 PS interviews, responses to singular elicitation are with a general genre. Also, the PSs respond to the elicitation question in the plural with a plural genre, which contrasts with how the GP group handles questions in the plural. The GPs do produce general genres on the basis of elicitation questions in the singular ( 3 of 
11), however, this tendency seems overruled by the fact that they predominantly seek the specific genre no matter the phrasing of the question.

\section{Taking on the task?}

In many of the interviews, the speakers produce a genre immediately after the interviewer's elicitation question. In some interviews, however, the doctors negotiate the elicitation question before producing a genre. The negotiation may be any inserted talk between the elicitation question and the start of the narrative genre, such as clarifying questions from the interviewees as seen in (5), which is an instance of negotiation (PS5):

1 INT: Do you remember like a \# typical \# patient with the: unipolar depression \# 2 INF: yes I have just had one ehm here oh with a unipolar! are you asking for now here <INT: 3 \# yes ehm> \# right \# <INT: \# yes>

4 INT: it can also be the other type

5 INF: oh it was \{just because\} the other <INT: \# ehm yes \#> I was thinking about the other

$6<\mathrm{INT}$ : \# yes yes yes $>$

7 INT: but you \#

8 INF: ehm \#<INT: \# can also tell about that $>$ \# ehm well what now what what now then

9 \{then\} now I have just lost the thread because now now now s- you asked xxx $<$ INT: no yes I 10 was asking if $>$

11 INT: you could remember a \# like a \# patient you thought was typical with regard and there I 12 was actually thinking about the un- unipolar but I would $<$ INF: \#unipolar yes \#> also like to 13 hear about the other one \#

14 INF: yes

15 INT: yes \#

16 INF: : ehm but it is more I actually think the unipolar is the most interesting to you because $17<$ INT: \# yes yes $>$ because it is the one that i:s most \# it is that type tha:t comes into general 18 practice $<\mathrm{INT}$ : \# yes \#> typically right $<\mathrm{INT}$ : \# yes \#> \# ehm yes \# we:11 I remember a lot so 19 what is it that you would like to know then I can \# <INT: \# yes but I would like to know>

20 INT: kind of ehm it it ehm and of course that is probably not the typical kind but ha well 
21 when I am asking for a typical patient then it is <INF: \# yes \#> a kind of a picture that \# that 22 mirrors \#

23 INF: yes \# <INT: what>

24 INT: you would \# think it is \# it is what you often see right \# yes <INF: \# okay \#> \#

(PS5)

A count of the negotiations that take place after the elicitation question in the interviews shows a difference between the two groups. Whereas 7 of 11 GPs produce a genre immediately after the elicitation question, this is only the case in 4 of the 9 possible PS responses. Excerpt (5) is taken from a PS interview and conveys an extended negotiation, where nine turns are inserted before the genre is produced. This negotiation could be regarded as a wish to provide precise information, fulfilling the purpose of the speech event (the interview), and ultimately the research project, by ensuring the interviewer's takeaway from the interview. This is also supported by the PS's counter-question: "What is it that you would like to know?" (1. 19), along with the extensive use of meta-language throughout the sequence, which underlines the PS's focus on identifying the task given by the interviewer. Further, the story is realized as a general account, which supports our assertion that the PSs tend to conceptualize patients in categorical terms rather than in specific encounters. The predominance of negotiation in the PS group could be seen as an affirmation of the professional identity they possess as experts, as opposed to the GPs. In (5), the PS even decides what the most valuable information for the interviewer would be (11. 16-18).

\section{Discussion: Is shared care possible?}

\section{Different linguistic patterns as an indication of different conceptualizations of depression}

The starting point for this study was the need for new evidence about the understanding of depression in the primary and secondary health sectors with the perspective of creating possibilities for shared care between general practice and psychiatry. Different reviews have shown that shared care is associated with sig- 
nificant improvement in depression compared with usual care (Smith et al 2017; Sighinolfi et al 2014; Archer et al 2012). Nevertheless, there seem to be covert barriers between the two groups of professionals (Gask 2005), which could hamper enhanced collaboration (Overbeck, Kousgaard \& Davidsen, 2018b). The analyses of the two groups' representations of patients in combination with interactional phenomena in the interviews have suggested differences in the ways the GPs and the PSs conceptualize patient identities, along with their own professional identities. The divide between specific and general representations was particularly prevalent in the interviews. The result that the GPs tend to conceptualize specific patients indicates that the GPs take a more individual approach to patients. Dimensions such as specific life-circumstances, critical events and causes etc. are central in establishing a helpful and full-bodied picture of the patient. An explanation for these different preferences in the two groups may be found in the circumstances under which they meet their patients. GPs often have a longstanding relationship with patients, which could explain why they render specific patients to a greater degree than the PSs, whose training focuses on achieving competence in diagnoses and medication (Stange 2009). The results also mirror the circumstance that patients in GP consultations are un-referred, often with undifferentiated symptoms, implying a patient-centred approach where the patient sets the agenda (Langberg, Dyhr \& Davidsen 2019). In contrast, the purpose of psychiatric consultations is to decide whether or not a given condition is present, implying that the PSs' focus is on the diagnosis rather than on the patients themselves.

A central issue is: to what degree this mindset of the GPs and their approach to patients can be integrated into shared care between sectors (Overbeck, Kousgaard \& Davidsen 2018a). The GPs must refer to diagnostic criteria formulated in psychiatry (Gask, Klinkman, Fortes \& Dowrick 2008), but they do not always consider these criteria relevant in general practice (e.g. Davidsen \& Fogtmann 2014b). In the Danish Collaborative Care study, the GPs thought that the diagnostic criteria for being included in the project were too rigid and did not mirror the clinical reality in general practice (Overbeck, Kousgaard \& Davidsen 2018a). In the study, psychiatric nurses, employed in secondary care psychiatry, treated patients in general practice (Brink-Claussen et al. 2017). Dialogue between the sectors was mostly monological with the psychiatric nurses giving reports. On the rare occasions that dialogical communication took place, with mutual contributions from GPs and care managers, there was a development of a shared understanding (Overbeck, Kousgaard \& Davidsen 2018b). Another study of the GP and PS interviews de- 
monstrated significant differences in the two groups' grammatical uses of depression terminology (Pedersen 2018). These differences can also be seen as manifestations of diverging understandings of depression and seem to confirm a lack of integration of understandings between psychiatry and general practice. This could possibly hamper collaboration about patients and increase rejection of GPs' referrals to psychiatry (May 2013).

\section{The interview as an interactional discipline}

The present study also showed differences in interactional patterns in the two groups of doctors. These differences were manifested in varying approaches to the interviewer and the interview situation, just as subtle variations in the interviewer's interview technique may have contributed to slightly different results within the two groups. These interactional observations add to the notion that the two groups have diverging professional identities. The different interactional structures can be illuminated further by looking at the context i.e. the research interview. Kvale argues that:

"The research interview is an inter-view where knowledge is constructed in the interaction between two people. The interviewer and the subject act in relation to each other and reciprocally influence each other. The knowledge produced in a research interview is constituted by the interaction itself, in the specific situation created between an interviewer and an interviewee. With another interviewer, a different interaction may be created and a different knowledge produced." (Kvale 2007: 11-13)

The differences between the two groups, not only in terms of representation but also in how the representations are fueled in the interaction, could be supported by Kvale's observation. The relation between the interviewer, who has a long history as a GP, and the doctors could be a local, contextually motivated realization of broader professional, and not least cultural, takes on depression and patients with depression.

Two studies of the same 23 doctors' interactions with their patients based on video-recordings of consultations have shown that GPs and PSs have different approaches to interacting with their patients (Davidsen \& Fosgerau 2014a, Fosgerau \& Davidsen 2014). One of the studies looked at how the doctors had different ways of handling patients' emotional disclosures, and concluded that: 
"The differences between GPs and psychiatrists might mirror deeper differences in the conceptualization of depression as a biomedical disease or a condition caused by life circumstances [...] A lack of consensus might affect fruitful interdisciplinary work." (Davidsen \& Fogtmann 2014a: 66).

The evidence from the current and previous studies that the two groups display different grammatical, narrative and interactional patterns could indicate that practical and structural factors in the healthcare sectors do not provide a full explanation for these findings. Instead, the difference between the two groups could be suggestive of more fundamental cultural differences between the two sectors, partly caused by their different roles and working conditions in the health care system (Stange 2009, Stange \& Ferrer 2009, McWhinney 1996), which could pose a challenge to future cooperation.

\section{Conclusion}

In this study, we have demonstrated that the GPs present a more substantial and personal picture of their patients with depression than do the PSs. These representations of patients, as well as interactional patterns, could be indicative of GP and PS approaches to depression as an illness, to patients and treatment and, ultimately, to the foundation for shared care. By providing precise structural descriptions of health care interview discourse, our linguistic approach may be considered a methodological alternative to more qualitative, thematically based methods within the field of social medicine, just as we expect that linguistic analyses of health care interviews may prove fruitful in future collaboration across academic disciplines.

\section{Notes}

1 The interview guide was suggestive rather than prescriptive, consisting of conversational topics rather than specific questions with a certain wording. Hence, in two of the interviews, the interviewer did not pose the question about a typical patient with depression.

2 Of the 12 GPs, 11 produced a genre when asked the elicitation question, whereas one attempt was unsuccessful. 
3 Of the 11 PSs, two were not presented with the elicitation question, which makes a total of 9 PS speech genres.

4 In cases of ambiguity as regards the singular/plural distinction, it is the last part of the question - i.e. how the interviewer ends up phrasing the question - that has been included in the count.

\section{Litterature}

Archer, J., Bower, P., Gilbody, S., Lovell, K., Richards, D., Gask, L., Dickens, C., \& Coventry, P. (2012). Collaborative care for depression and anxiety problems. Cochrane Database of Systematic Reviews, 10. doi:10.1002/14651858.CD006525.pub2.

Bamberg, M. (2010). Who am I? Narration and its contribution to self and identity. Theory E Psychology, 21(1), 1-22. https://doi.org/10.1177/0959354309355852

Brinck-Claussen, U. O., Curth, N. K., Davidsen, A. S., Mikkelsen, J. H., Lau, M. E., Lundsteen, M., Csillag, C., Christensen, K. S., Hjorthøj, C., Nordentoft, M., \& Eplov, L. F. (2017). Collaborative care for depression in general practice: Study protocol for a randomised controlled trial. Trials, 18(1), 344. doi: 10.1186/s13063-017-2064-7

Bruner, J. (2002). Making Stories. Law, Literature, Life. Cambridge, MA: Harvard University Press.

Bruner, J. (1986). Actual Minds, Possible Worlds. Cambridge, MA: Harvard University Press.

Clan transcription conventions: https://dgcss.hum.ku.dk/aarsberetninger/rapporter/clan-oversigt.pdf/Clan-oversigt1.pdf.). Retrieved October 24, 2018.

Chew-Graham, C.A., May, C.R., \& Headley, S. (2000). The burden of depression in primary care: A qualitative investigation of general practitioners' constructs of depressed people in the inner city. International Journal of Psychiatry in Clinical Practice, 6(4), 137-141. doi:10.1185/135525700543352

Coventry, P. A., Lovell, K., Dickens, C., Bower, P., Chew-Graham, C., Cherrington, A., Garrett, C., Gibbons, C. J., Baguley, C., Roughley, K., Adeyemi, I., Keyworth, C., Waheed, W., Hann, M., Davies, L., Jeeva, F., Roberts, C., Knowles, S., \& Gask, L. (2012). Collaborative Interventions for Circulation and Depression (COINCIDE): Study protocol for a cluster randomized controlled trial of collaborative care for depression in people with diabetes and/or coronary heart disease. Trials, 13:139. doi: 10.1186/1745-6215-13-139

Davidsen, A. S. (2008). Mentalization, Narrative and Time - A qualitative study about psychological interventions in general practice (PhD thesis). Copenhagen: The Research Unit of General Practice.

Davidsen, A.S., \& Reventlow, S. (2011). Different approaches to understanding patients in general practice in Denmark: A qualitative study, British Journal of Guiding and Counselling, 39(3), 209-226. https://doi.org/10.1080/03069885.2011.552600

Davidsen, A. S., \& Fosgerau, C. F. (2014a). General practitioners' and psychiatrists' responses to emotional disclosures in patients with depression. Patient Education and Counseling, 95(1), 61-68. doi: 10.1016/j.pec.2013.12.018 
Davidsen, A. S., \& Fosgerau, C. F. (2014b). What is depression? Psychiatrists' and GPs' experiences of diagnosis and the diagnostic process. International Journal of Qualitative Studies on Health and Well-Being, 9(1), [24866]. doi: 10.3402/qhw.v9.24866

Dowrick, C. (2009). Beyond depression - a new approach to understanding and management. New York: Oxford University Press. https://doi.org/10.1093/med/9780199545292.001.1

Eggins, S., \& Slade, D. (1997). Analysing Casual Conversation. London: Cassell.

Eplov, L.F., Lundsteen, M., \& Birket-Smith, M. (2009). Shared care for ikke-psykotiske sygdomme. Anbefalinger på baggrund af en systematisk litteraturundersøgelse. Copenhagen: Danske Regioner.

Eplov, L. F., Davidsen, A. S., Christensen, K. S., Mikkelsen, J. H., Lau, M., Nielsen, J. N., et al. (2014). Project Collabri. The effect of a Danish model of collaborative care for people with anxiety and depression in general practice. Retrieved September 25, 2014, from http://www. psykiatri-regionh.dk/menu/Forskning+og+udvikling1/Udvikling/Projekt+Collabri/

Fosgerau, C. F., \& Davidsen, A. S. (2014). Patients' perspectives on antidepressant treatment in consultations with physicians. Qualitative Health Research, 24, 641-653. doi: $10.1177 / 1049732314528813$

Gask, L. (2005). Overt and covert barriers to the integration of primary and specialist mental health care. Social Science \& Medicine 61(8), 1785-94. doi:10.1016/j.socscimed.2005.03.038

Gask, L., Klinkman, M., Fortes, S., \& Dowrick, C. (2008). Capturing complexity: The case for a new classification system for mental disorders in primary care. European Psychiatry, 23(7), 469-476. doi:10.1016/j.eurpsy.2008.06.006

Gregersen, F., \& Barner-Rasmussen, M. (2011). The logic of comparability: On genres and phonetic variation in a project on language change in real time. Corpus Linguistics and Linguistic Theory, 7(1), 7-36. doi:10.1515/CLLT.2011.002

Jensen, U. J., \& Mattingly, C. (2009). Narrative, self and social practice. Aarhus: Philosophia Press.

Kvale, S. (1997). InterView. Copenhagen: Hans Reitzels Forlag.

Kvale, S. (2007). Doing interviews. Thousand Oaks: Sage Publications. https://doi. org $/ 10.4135 / 9781849208963$

Labov, W., \& Waletzky, J. (1967). Narrative analysis: Oral versions of personal experience. Journal of Narrative and Life History, 7, 1-38. https://doi.org/10.1075/jnlh.7.02nar

Labov, W. (1972). Sociolinguistic patterns. Philadelphia: University of Pennsylvania Press.

LANCHART (2011). Coding manual for Discourse Context Analysis: http://dgcss.hum.ku.dk/ aarsberetninger/rapporter/IIVkodningsmanual__opdateret_januar_2011___2_.pdf/ Retrieved October 24, 2018.

Langberg, E., Dyhr, L. Davidsen, A. (2019). Development of the concept of patient-centredness - A systematic review. Patient Education and Counseling. doi:10.1016/j.pec.2019.02.023

May, C. (2013). Towards a general theory of implementation. Implementation Science, 8(18). doi:10.1186/1748-5908-8-18

McWhinney, I. R. (1996). The importance of being different. British Journal of General Practice, 46(408), 433-436.

Nielsen, S. B. (2010). Konversationsanalyse af læge-patient-samtaler: status, overblik og muligheder. NyS. Nydanske Sprogstudier, 38(38), 10-37. https://doi.org/10.7146/nys. v38i38.13517 
Overbeck, G., Davidsen, A. S., \& Kousgaard, M. B. (2016). Enablers and barriers to implementing collaborative care for anxiety and depression: a systematic qualitative review. Implementation science, 11(1), 165. doi:10.1186/s13012-016-0519-y

Overbeck, G., Kousgaard, M. B., \& Davidsen, A. S. (2018a). The work and challenges of care managers in the implementation of collaborative care: A qualitative study. Journal of Psychiatric and Mental Health Nursing, 25(3), 167-175. doi:10.1111/jpm.12449

Overbeck, G., Kousgaard, M. B., \& Davidsen, A. S. (2018b). Enactments and experiences of 'enhanced interprofessional communication' in collaborative care - a qualitative study. Journal of Interprofessional Care, doi:10.1080/13561820.2018.153810

Pedersen, H. S. (2018). Grammatisk talesprogsanalyse som tilgang til at studere forståelser af depression. Gengivet sprogbrug som eksempel. NyS, Nydanske Sprogstudier, (1)54, 156-182.

Richards, D. A., Bower, P., Chew-Graham, C., Gask, L., Lovell, K., Cape, J., Pilling, S., Araya, R., Kessler, D., Barkham, M., Bland, J. M., Gilbody, S., Green, C., Lewis, G., Manning, C., Kontopantelis, E., Hill, J. J., Hughes-Morley, A., \& Russell, A. (2016). Clinical effectiveness and cost-effectiveness of collaborative care for depression in UK primary care (CADET): A cluster randomised controlled trial. Health Technology Assessment, 20(14), 1-192. doi:10.3310/hta20140

Ricoeur, P. (1980). Narrative time. Critical Inquiry, 7(1), 169-190. https://doi.org/10.1086/448093

Sarbin, T. R. (1986). Narrative psychology, the storied nature of human conduct. New York: Praeger.

Schafer, R. (1980). Narration in the psychoanalytic dialogue. Critical Inquiry, 7(1), 29-53. https://doi.org/10.1086/448087

Sighinolfi, C., Nespeca, C., Menchetti, M., Levantesi, P., Belvederi Murri, M., \& Berardi, D. (2014). Collaborative care for depression in European countries: A systematic review and meta-analysis. Journal of Psychosomatic Research, 77(4), 247-263. doi:10.1016/j. jpsychores.2014.08.006

Smith, J. A., \& Osborn, M. (2003). Interpretative phenomenological analysis. In J. A. Smith (Ed.), Qualitative psychology, 51-80. London: Sage.

Smith, S.M, Cousins, G., Clyne, B., Allwright, S., \& O’Dowd, T. (2017). Shared care across the interface between primary and specialty care in management of long term conditions. Cochrane Database of Systematic Reviews, 2. doi:10.1002/14651858.CD004910.pub

Stange, K. C. (2009). The generalist approach. Annals of Family Medicine, 7(3), 198-203. doi:10.1370/afm.2145 https://doi.org/10.1370/afm.2145

Stange, K. C., \& Ferrer, R. L. (2009). The paradox of primary care. Annals of Family Medicine, 7(4), 293-299. doi:10.1370/afm.1023 https://doi.org/10.1370/afm.1023

White, M.K. (2007). Maps of narrative practice, New York and London: W. W. Norton \& Company. 